\title{
A QUESTÃO AGRÁRIA, ESTADO E POLÍTICAS PÚBLICAS PARA O CAMPO NO BRASIL
}

Kleber Rodrigo Penteado ${ }^{1}$

Sedeval Nardoque ${ }^{2}$

RESUMO: A questão agrária latente no Brasil é resultado dos conflitos de classe no seio do território. O objetivo deste artigo é discutir sobre a questão agrária brasileira contemporânea e as políticas públicas voltadas para o campo. Para isto, Estado e território são entendidos como resultados da luta de classes construída historicamente, na qual, o primeiro representa os interesses das classes dominantes que o compõe, e, o segundo é a expressão concreta das relações capitalistas e suas articulações superestruturais. Discute-se as estratégias de planejamento descentralizado adotadas pelo Estado brasileiro em consonância com as proposições dos órgãos internacionais de crédito como o Banco Mundial e o FMI. Por fim, trata-se da Reforma Agrária e de algumas das consequências impresumíveis do avanço das políticas neoliberais, especialmente pós-golpe de 2016.

PALAVRAS-CHAVE: Estado; Território; Reforma Agrária; Planejamento territorial; Políticas públicas.

\section{THE AGRARIAN QUESTION, STATE AND PUBLIC POLICIES FOR THE FIELD IN BRAZIL}

ABSTRACT: The latent agrarian question in Brazil is the result of class conflicts within the territory. The purpose of this article is to discuss the contemporary Brazilian agrarian issue and public policies aimed at the countryside. For this, State and territory are understood as results of the historically constructed class struggle, in which the first represents the interests of the dominant classes that compose it, and the second is the concrete expression of capitalist relations and their superstructural articulations. It discusses the decentralized planning strategies adopted by the Brazilian State in line with the proposals of international credit agencies such as the World Bank and the IMF. Finally, it is about Agrarian Reform and some of the negative consequences of the advance of neoliberal policies, especially after the 2016 coup.

KEYWORDS: State; Territory; Agrarian reform; Territorial planning; Public policy.

\footnotetext{
1 Instituto Federal de Mato Grosso do Sul (IFMS)/Universidade Federal de Mato Grosso do Sul (UFMS) - kleber.penteado@ifms.edu.br

2 Universidade Federal de Mato Grosso do Sul (UFMS) - sedeval.nardoque@ufms.br
} 


\section{LA CUESTIÓN AGRARIA, ESTADO Y POLÍTICAS PÚBLICAS PARA EL CAMPO EN BRASIL}

RESUMEN: La cuestión agraria latente en Brasil es el resultado de conflictos de clases dentro del territorio. El propósito de este artículo es discutir la problemática agraria brasileña contemporánea y las políticas públicas dirigidas al campo. Para ello, Estado y territorio se entienden como resultado de la lucha de clases históricamente construida, en la que el primero representa los intereses de las clases dominantes que lo componen, y el segundo es la expresión concreta de las relaciones capitalistas y sus articulaciones superestructurales. Se analizan las estrategias de planificación descentralizada adoptadas por el Estado brasileño en línea con las propuestas de organismos internacionales de crédito como el Banco Mundial y el FMI. Finalmente, se trata de la Reforma Agraria y algunas de las consecuencias negativas del avance de las políticas neoliberales, especialmente después del golpe de 2016.

PALABRAS CLAVE: Gobierno Estatal; Territorio; Reforma Agraria; Planificación territorial; políticas públicas.

\section{INTRODUÇÃO}

O presente artigo foi realizado com apoio da Coordenação de Aperfeiçoamento de Pessoal de Nível Superior - Brasil (CAPES) e é resultado parcial das reflexões realizadas a partir de estudos feitos durante o curso de Doutorado no Programa de Pós-Graduação em Geografia (PPGGEO) da Universidade Federal de Mato Grosso do Sul (UFMS), campus Três Lagoas (CPTL), e tem por objetivo discutir acerca questão agrária brasileira contemporânea e as políticas públicas voltadas para o campo.

Para tanto, primeiramente, busca-se esboçar os delineamentos conceituais inerentes à discussão do Estado e do território, depois, são discutidos os desdobramentos relacionados às ações de sujeitos sociais ligados a duas categorias de análise: o agronegócio e o campesinato. Por fim, discute-se o planejamento descentralizado e o avanço das políticas neoliberais sobre as conquistas sociais dos movimentos socioterritoriais no campo brasileiro.

ESTADO, TERRITÓRIO E QUESTÃO AGRÁRIA. 
De início, é preciso compreender o Estado como instituição resultante das construções históricas de cada povo e, nos últimos séculos, em determinado estágio de transformações no interior do modo capitalista de produção. É necessário compreendê-lo, também, que, por ser produto da luta de classes e de frações de classe, não é neutro, mas representa os interesses das classes dominantes na constituição do poder estatal (HARVEY, 2005; JESSOP, 2009).

A composição heterogênea do Estado por diferentes classes e suas frações intraclasse favorece o domínio das economicamente dominantes (capitalistas e latifundiários) em relação à trabalhadora (trabalhadores e camponeses) devido à capacidade de mobilização de recursos e estratégias para se tornarem também as politicamente dominantes. Essas classes economicamente dominantes exercem seu poder de acordo com seus interesses, mas têm capacidade de fazer parecer que são universalizados para toda sociedade (HARVEY, 2005; JESSOP, 2009; NARDOQUE, 2017).

Outro elemento bastante caro para as discussões a serem tomadas neste texto diz respeito à categoria de análise geográfica "território" da qual se desdobra o processo de territorialização.

Entende-se o território como síntese contraditória, totalidade concreta das relações capitalistas e suas articulações superestruturais mediadas pelo Estado, uma unidade dialética da espacialidade que a sociedade tem e desenvolve, um produto concreto da luta de classes (OLIVEIRA, 1999). Neste contexto, é possível a ocorrência do processo de territorialização do capital no campo, o qual implica a consolidação de apropriação sobre frações do território de outrem por meio da sua dominação representada pela posse ou domínio via compra ou pelo arrendamento de terras, apropriando-se da renda da terra na produção (MARTINS, 1981; OLIVEIRA, 1999; NARDOQUE, 2016), como é o caso das ações de grandes grupos econômicos que controlam desde a produção até a circulação de produtos de origem agropecuária. Por outro lado, nas atividades agropecuárias 
de menor renda na produção, as ações das grandes empresas ocorre com a monopolização do território, ou seja, a apropriação da renda da terra na circulação das mercadorias, sobretudo no momentos que os agricultores colocam sua produção no mercado. Os atravessadores e/ou as grandes empresas atuam no sentido de monopolizarem o território, mas sem o apropriarem, apropriandose da produção agropecuária, como é o caso do leite, das frutas, das hortaliças, dentre outros (OLIVEIRA, 1999; NARDOQUE, 2016; NARDOQUE 2017).

No interior do Estado, são geradas e geridas as condições para gestão e reprodução do território. Trata-se de processos orquestrados pelos sujeitos representativos de cada fração de classe que compõe o poder do Estado. Seus desdobramentos possuem a assinatura esperada por esses grupos às condições de reprodução ampliada do capital e dos processos de exploração, tanto da força de trabalho, quanto de apropriação da renda fundiária. Esta última é a forma que as empresas capitalistas possuem de superar o entrave representado pela propriedade da terra para a expansão do capital. A realização da renda fundiária é, segundo Martins (1981), a forma de o capitalista utilizar (se apropriar) da terra e da mais valia social implícita nesta propriedade.

Para viabilizar a discussão de aspectos da questão agrária brasileira, é preciso compreender (ao menos basicamente) que existem, na produção do território no campo do Brasil, duas importantes categorias de análise: o agronegócio (com diferentes sujeitos de diferentes classes sociais, sobretudo proprietários fundiários em aliança com os capitalistas) e o campesinato. É sabido que estes não são os únicos sujeitos no campo e os debates da questão agrária brasileira, mas, dentro da discussão proposta, são tidos como importantes protagonistas do processo, tanto pela capacidade de mobilização política e financeira nos primeiros, quanto pela luta, resistência (para entrarem e permanecerem na terra) e resiliência dos segundos. Sendo assim, a definição 
destas categorias é bastante relevante para a compreensão da discussão que se segue.

As ações dos sujeitos vinculados ao agronegócio vinculam-se, sobremaneira, à produção agropecuária de commodities e outros produtos agrícolas realizada por grandes empresários ou por proprietários de terra que atendem aos interesses vinculados ao grande capital das corporações que buscam na sua expansão geográfica a forma de ampliação da exploração capitalista (ALMEIDA, PAULINO, 2000; PAULINO, 2008). Entende-se por camponês o sujeito que tem por base o trabalho familiar, ou seja, que tem como centro da mão de obra da produção o núcleo familiar e sua produção é voltada eminentemente para atender às demandas de autoconsumo e do mercado consumidor interno do país (ALMEIDA, PAULINO, 2000; PAULINO, 2008; FERNANDES, 2012; FABRINI, 2011).

No Brasil, as classes sociais vinculadas ao agronegócio conseguem mobilizar boa parte da política partidária no processo de construção das regras que tornam este grupo mais privilegiado no que diz respeito ao acesso a crédito e políticas públicas para fomentar sua reprodução, porém sem jamais deixarem de produzir a sensação que o atendimento de seus anseios corresponde ao das necessidades da grande massa da população (PAULINO, 2008). No que diz respeito aos camponeses, a mobilização, quando acontece, é seguida pela consciência de classe que implica em enfrentamento permanente com as relações capitalistas (FERNANDES, 2012), mas é importante ressaltar que os camponeses são diferentes entre si e nem todos possuem consciência de classe e, portanto, de seu papel no contexto político e econômico enquanto classe social (MITIDIERO JR, BARBOSA E SÁ, 2017).

Oliveira (1999), Paulino (2008), Martins (1981), Fernandes (2012), Nardoque (2016), Mattos (2017) e Mitidiero Jr, Barbosa, Sá (2017) evidenciam em suas discussões que, apesar de o agronegócio concentrar a maior parte das terras e 
grande parte do acesso aos fundos públicos de crédito, para desenvolvimento de suas atividades, o campesinato detêm o maior número de estabelecimentos rurais do país, dos empregos gerados e mantidos no campo, do uso eficiente da terra e dos recursos que dispõe para garantir sua reprodução enquanto modo de vida e classe.

Neste sentido, os processos de criação e recriação camponesa se tornam importantes porque tratam, ao mesmo tempo, da existência, reexistência e reprodução do campesinato.

A criação camponesa ocorre quando a população se organiza em movimentos sociais de luta pela terra, fazendo surgir novos camponeses que se inserem no contexto de lutas pela terra (uma espécie de êxodo rural às avessas) no qual, a partir da identificação com as causas camponesas ou com o modo de viver e produzir camponês ocorre a mudança (ou tentativa de mudança) para o campo a fim de se estabelecer nesse meio e obter dele seu sustento reforçado pela identidade com a terra e tendo com centro da produção a mão de obra familiar (FERNANDES, 2012).

Para Fernandes (2012), o processo de recriação camponesa corresponde ao retorno ao campo daqueles que, tendo vivido em outro momento lá, foram expropriados ou expulsos da terra, mas lutam para conseguir, de alguma forma, retornar para o campo ou já conseguiram e tentam reproduzir sua existência.

Fernandes (2012), Mattos (2017), Nardoque, Melo, Kudlavicz (2018) chamam atenção à falta de acesso aos recursos mínimos para reprodução das condições de vida dos camponeses que acabam dando origem à expropriação dos sujeitos da terra em decorrência das condições miseráveis impostas pelas relações capitalistas aos camponeses.

$\mathrm{Na}$ sequência, outro elemento importante a ser considerado no entendimento das discussões sobre a questão agrária ${ }^{3}$, é a ideia de política

\footnotetext{
${ }^{3} \mathrm{~A}$ propriedade, a posse, o uso e a renda da terra são os elementos centrais da questão agrária.
} 
pública, compreendida aqui como ação do Estado destinada a permitir o acesso de determinada classe ou fração de classe a recursos e condições que viabilizem sua reprodução enquanto classe e, consequentemente, o atendimento de demandas superestruturais relacionadas aos arranjos produtivos ligados aos setores diretamente atendidos por essas políticas (HARVEY, 2005; JESSOP, 2009; OLIVEIRA, 1999; NARDOQUE, 2016).

Sobre esse aspecto, é valido destacar que no Brasil o processo de industrialização da agricultura tem ocorrido junto com o processo de internacionalização da economia e subordinada à Divisão Internacional do Trabalho (DIT) e ao capital financeiro que condiciona os empréstimos ao atendimento da demanda de commodities e ao pagamento da dívida externa (OLIVEIRA, 1999).

Como consequência disso, as frações de classe, representadas no seio do poder estatal, mobilizam seus esforços para parecer que o cumprimento da cartilha ditada pelos órgãos de crédito internacional é também o anseio e a demanda de toda sociedade, enquanto, na prática, corresponde ao mecanismo de garantia da expansão geográfica do capital representado pelo ajuste espacial de expansão territorial do agronegócio, ampliando a capacidade produtiva e sua capacidade de exploração da mão de obra, aliada à manutenção da DIT e da condição de subdesenvolvimento de países como o Brasil (MARTINS, 1981; OLIVEIRA, 1999; HARVEY 2005; PAULINO, 2008; NARDOQUE, 2017).

Frente à mobilização das classes dominantes e de suas representações no interior do poder estatal, emerge do grupo de maior representatividade quantitativa (e menor representatividade política no interior do Estado brasileiro) a mobilização em forma de movimentos socioterritoriais de luta pela terra e pelos direitos de manutenção e permanência da reprodução das condições e existência na terra. Esses movimentos presentes no âmago camponês brasileiro representam os esforços de criação e recriação camponesa em busca de terra e 
recursos financeiros para permanência na terra via políticas públicas e de governo, consolidando o ideário de luta e anseio pelo processo de Reforma Agrária (OLIVEIRA 1999; HESPANHOL, 1999; ALMEIDA, PAULINO, 2000; ARAÚJO, 2003; FABRINI, 2011; NARDOQUE, 2016; NARDOQUE, 2017; LUIZ, NARDOQUE, 2019).

A questão agrária brasileira ganhou mais corpo e relevância após o processo de redemocratização do país e da maior articulação dos movimentos socioterritoriais do/no campo, como o Movimento dos Trabalhadores Rurais Sem Terra (MST). Apesar disso, a realização da Reforma Agrária no Brasil, enquanto consolidação do cumprimento legal da função social da terra e construção de mecanismos de garantia da permanência na terra, não é uma realidade porque convém às frações de classe, dominantes no interior do poder do Estado brasileiro, não alterar a estrutura fundiária concentrada sob o poder das grandes empresas e dos grandes proprietários de terra que, apesar de baixa eficiência produtiva ${ }^{4}$, possui alta eficiência política, contrariamente aos movimentos socioterritoriais de luta pela terra que se encontram em posição diametralmente oposta, mesmo com alta eficiência produtiva tem baixa representatividade política. Agindo assim, o Estado (que não é neutro) garante, além da manutenção da estrutura fundiária e dos interesses dos sujeitos do agronegócio, a capacidade de geração de superávit a partir do setor primário da economia, sobretudo em momentos de crise em que o setor é responsável por aumento das exportações (commodities) em prejuízo do mercado interno nacional, dando o tom das relações que se desenvolvem no campo brasileiro. (DELGADO, 2012; HESPANHOL, 1999; LUIZ, NARDOQUE, 2019; NARDOQUE, 2017; FABRINI, 2011; MITIDIERO JR, BARBOSA, SÁ, 2017).

\footnotetext{
${ }^{4}$ Sobre esta temática e seus desdobramentos Mitidiero Jr, Barbosa e Sá (2017) discutem dados do Censo Agropecuário do IBGE com recorte voltado para a produção de alimentos destinados ao mercado interno brasileiro e destacam a eficiência produtiva das pequenas propriedades rurais frente às grandes propriedades tendo como parâmetro o tamanho da área de produção e aos recursos estatais disponíveis para cada classe de propriedades.
} 


\section{POLÍTICAS PÚBLICAS PARA O CAMPO}

No Brasil os movimentos socioterritoriais de luta pela terra, por pressão resultante da resistência frente ao avanço das ações dos sujeitos vinculados ao agronegócio e das lutas por acesso à terra e aos mecanismos de manutenção e permanência na terra, conseguiram progredir em termos da discussão e da criação de políticas públicas voltadas para os camponeses (ARRETCHE, 1996; ARAÚJO, 2003; FABRINI, 2011; CLEMENTE， 2011; DELGADO， 2012; LUIZ, NARDOQUE, 2019).

Os mecanismos criados pelo Estado, a partir das reivindicações e pressões dos movimentos socioterritoriais, possuem relação com o crescimento do modelo econômico neoliberal imposto por instituições financeiras internacionais para concessão de crédito a países de industrialização tardia como o Brasil e outros países latino-americanos. Os esforços liberalizantes realizados pelo Estado brasileiro estão representados na adoção de estratégias de planejamento descentralizado seguindo a cartilha proposta por instituições como Banco Mundial (BM) e o Fundo Monetário Internacional (FMI), como tentativa de solução para os problemas econômicos e sociais presentes não somente no campo, mas em todo território ou, pelo menos, na criação de um discurso globalizante capaz de fazer parecer que os anseios do capital internacional, em seu processo de expansão territorial, também atende aos anseios e, sobretudo, às necessidades das demais classes sociais (ARRETCHE, 1996; HESPANHOL, 1999; ARAÚJO, 2003; FABRINI, 2011; CLEMENTE, 2011; DELGADO, 2012; LUIZ, NARDOQUE, 2019).

Os esforços descentralizadores, materializados em forma de políticas de governo ou políticas de Estado no Brasil, podem ser vistos sob diferentes ópticas. Se por um lado o planejamento territorial descentralizado pode ser visto pelos órgãos de crédito internacional e pelas empresas transnacionais como parte do processo de transferência da responsabilidade estatal e de liberalização econômica, por outro, os movimentos sociais enxergam neste tipo de 
planejamento uma forma de democracia de base territorial na qual a gestão do território emana de demandas trazidas de baixo para cima (ARRETCHE, 1996; HESPANHOL, 1999; ARAÚJO, 2003; FABRINI, 2011; CLEMENTE, 2011; DELGADO, 2012; LUIZ, NARDOQUE, 2019).

O Estado brasileiro, historicamente executor e centralizador de decisões, assim como em outros países latino-americanos, age espacialmente de modo desigual, criando ou reforçando polos de desenvolvimento regional e, por consequência, reproduzindo e reforçando as desigualdades que colaboram com o enfraquecimento do planejamento de base local (descentralizado). Isso ocorre por ignorar que as regiões (e os lugares) resultam de relações historicamente construídas e demandam conhecimento crítico de seu processo evolutivo associado a levantamentos multidisciplinares com foco não apenas no crescimento econômico, mas no bem estar social tanto na esfera local quanto na regional. Por não ser considerado central, o bem estar social local e regional, quando existe, acaba ocorrendo como compensações do processo de descentralização e do desenvolvimento econômico (ARRETCHE, 1996; HESPANHOL, 1999; ARAÚJO, 2003; DELGADO, 2012; LUIZ, NARDOQUE, 2019).

A abordagem territorial (planejamento descentralizado) pode ser considerada um significativo avanço em termos de discurso e desenvolvimento teórico, entretanto, ainda não representa grande mudança prática em termos de política pública, do desenvolvimento territorial e da questão agrária no Brasil, justamente porque o contexto histórico de dominação e subserviência torna os interessados diretos no processo incapazes de tomar iniciativas frente às possibilidades que são postas pelos planejadores de políticas públicas, abrindo espaço para que os conselhos de base local sejam tomados (em sua maioria) pelas elites locais que subvertem estes espaços em retóricas de legitimação de seus interesses. (ARRETCHE, 1996; CLEMENTE, 2011; ORTEGA, CERQUEIRA，SILVA, 2016). 
As ações do Estado como indutor de políticas públicas, sobretudo de cunho territorial, ainda são insipientes, comparando-se com aquelas adotadas na União Europeia. Esse processo de descentralização por ausência ou pouca atuação, pode aumentar as desigualdades no planejamento territorial e, por mais que haja exemplos de implantação do modelo, como na Itália e em outros países da União Europeia ${ }^{5}$, os esforços brasileiros neste sentido ainda trabalham com "territórios fictícios", ignorando os interesses de grupos/classes e as contradições referentes ao processo de apropriação de terras e de recursos, criando uma espécie de miopia estatal das lutas políticas e de classes em diferentes escalas e contextos que, assim como a falta de identidade das bases com este modelo de política, inviabiliza a implantação e o desenvolvimento prático do planejamento e execução descentralizados que tem no Estado o principal indutor e credor do conjunto de estruturas de desenvolvimento de base local (ARRETCHE, 1996; ORTEGA, CERQUEIRA, SILVA, 2016; CLEMENTE, 2011).

Ao avaliar a questão agrária brasileira contemporânea, exposta por Oliveira (1999), Clemente (2011), Delgado (2012), Nardoque (2016), Ortega, Cerqueira, Silva (2016), Nardoque (2017), Paula, Gomez, Tracz (2017) e Luiz, Nardoque (2019), é possível perceber que, a partir dos anos 1990, ocorreram avanços com a criação ou ampliação de políticas públicas voltadas para os camponeses. Obviamente, nenhuma delas passou a existir de forma gratuita e sem lutas ou conflitos de interesse com outros sujeitos e com o próprio Estado. Entretanto, é válido ressaltar que, apesar dos avanços resultantes das lutas camponesas e do engajamento de diferentes sujeitos em torno da questão agrária brasileira, os autores supracitados esclarecem que os sujeitos vinculados ao agronegócio foram tão mais beneficiados quanto ao campesinato, à medida que os governos que se

\footnotetext{
5 "Terceira Itália" e "Leader" são exemplos de iniciativas de planejamento descentralizado exitosos em território europeu. O primeiro, baseado em características regionais peculiares, forte articulação cidade-campo e formação de clusters. O segundo, inicialmente, mais voltado para áreas com algum atraso de desenvolvimento e focado nas inciativas bottom up com forte planejamento (Clemente, 2011).
} 
estabeleceram no Brasil se encarregaram de reproduzir a estrutura fundiária concentrada e de poucos esforços no sentido de avançar com a Reforma Agrária de fato.

Sobre o processo de Reforma Agrária, algumas nuances do termo podem se compreender, pois, apesar de, em linhas gerais, sempre se tratar de um mesmo processo, existem diferenciações. Para os movimentos socioterritoriais de luta pela terra, a ideia está relacionada à desapropriação de terras improdutivas em prol do cumprimento de sua função social. Entretanto, nem sempre a Reforma Agrária se dá desta maneira e Coca e Fernandes (2009) elencam 12 mecanismos para obtenção de territórios de assentamentos rurais com base no Banco de Dados da Luta pela Terra (DATALUTA) e na legislação referente ao tema ${ }^{6}$. Os autores apontam que, apesar de a desapropriação ser uma das formas mais utilizadas, a Reforma Agrária no Brasil não se resume à adoção deste dispositivo. Estratégias, como a compra de terras e a concessão de crédito para compra de terras, são alternativas executadas pelo Estado brasileiro em diferentes momentos da história recente e, entretanto, são processos criticados pelos movimentos socioterritoriais e por pesquisadores da questão agrária brasileira (FABRINI, 2011; DELGADO, 2012; NARDOQUE, 2016; NARDOQUE, 2017; PAULA, GOMEZ, TRACZ, 2017; MATTOS, 2017; CLEPS JR, 2018; NARDOQUE, MELO, KUDLAVICZ, 2018; LUIZ, NARDOQUE, 2019).

A questão agrária no Brasil esteve presente nos debates e nos discursos no interior do Estado brasileiro ao longo dos governos durante os anos 1990, 2000 e até meados dos 2010. É certo que nem sempre esta presença foi materializada na correspondência dos anseios dos diferentes sujeitos do campo brasileiro em sua plenitude, mas não se pode negar que, em comparação com períodos anteriores da história do país, estes períodos citados representaram avanços práticos e

\footnotetext{
${ }^{6}$ Os mecanismos destacados pelos autores são: Adjudicação, Arrecadação, Cessão, Compra e venda, Confisco, Desapropriação, Discriminação, Doação, Incorporação, Reconhecimento, Transferência e Reversão de domínio.
} 
teóricos no que tange à temática. Os dados sobre assentamentos rurais criados e reconhecidos de 1985 a 2019 expostos no gráfico 1 ajudam a perceber uma parte deste processo.

Gráfico 1 - Brasil: Assentamentos Rurais Criados e Reconhecidos 1985-2019

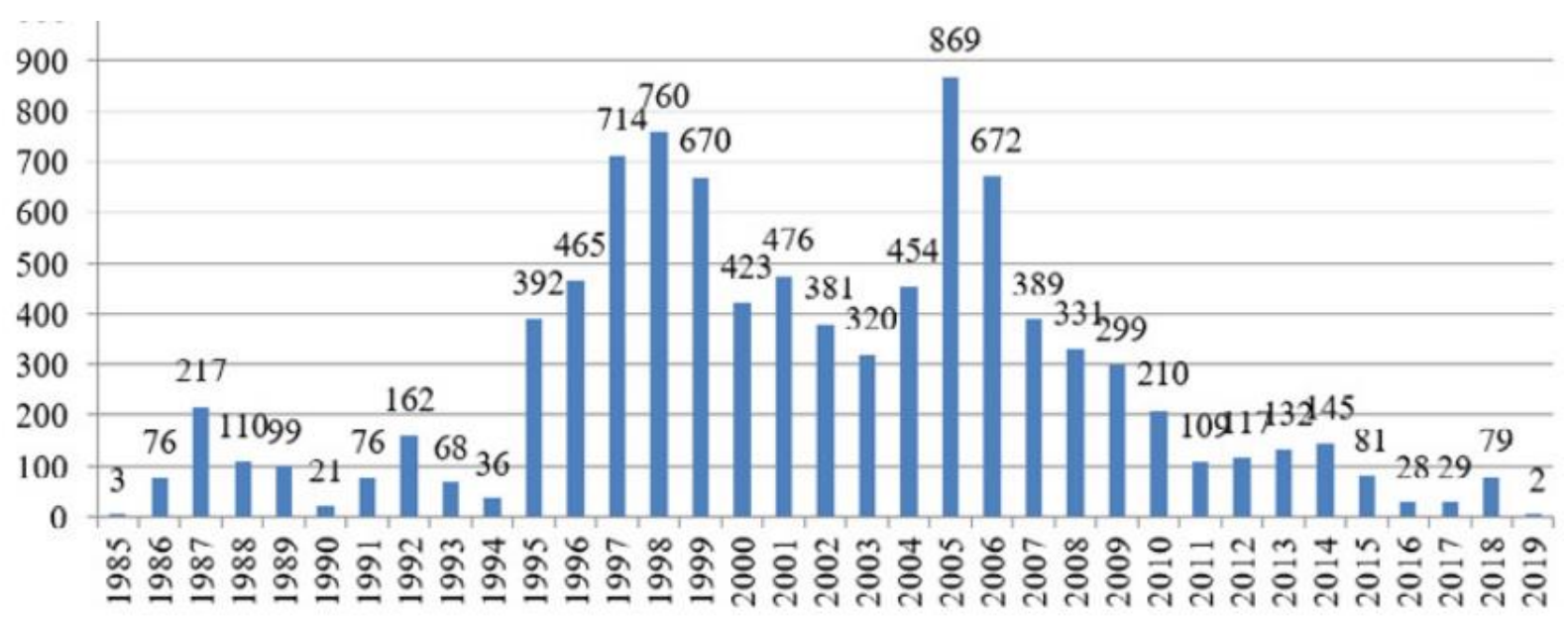

Fonte: INCRA. Elaborado por: Alentejano (2020)

Notadamente, o período de 2010 a 2015 representou redução significativa no número de assentamentos, mas, a partir de 2016, quando teve início do golpe Político-Jurídico-Midiático-Ruralista, foi evidente o drástico arrefecimento do número de assentamentos, acompanhado dos severos cortes nos recursos disponibilizados para a Reforma Agrária, conforme ilustra o gráfico 2.

Gráfico 2 - Brasil: dados orçamentários sobre a Reforma Agrária em milhões de Reais $(R \$)-2013$ a 2018 


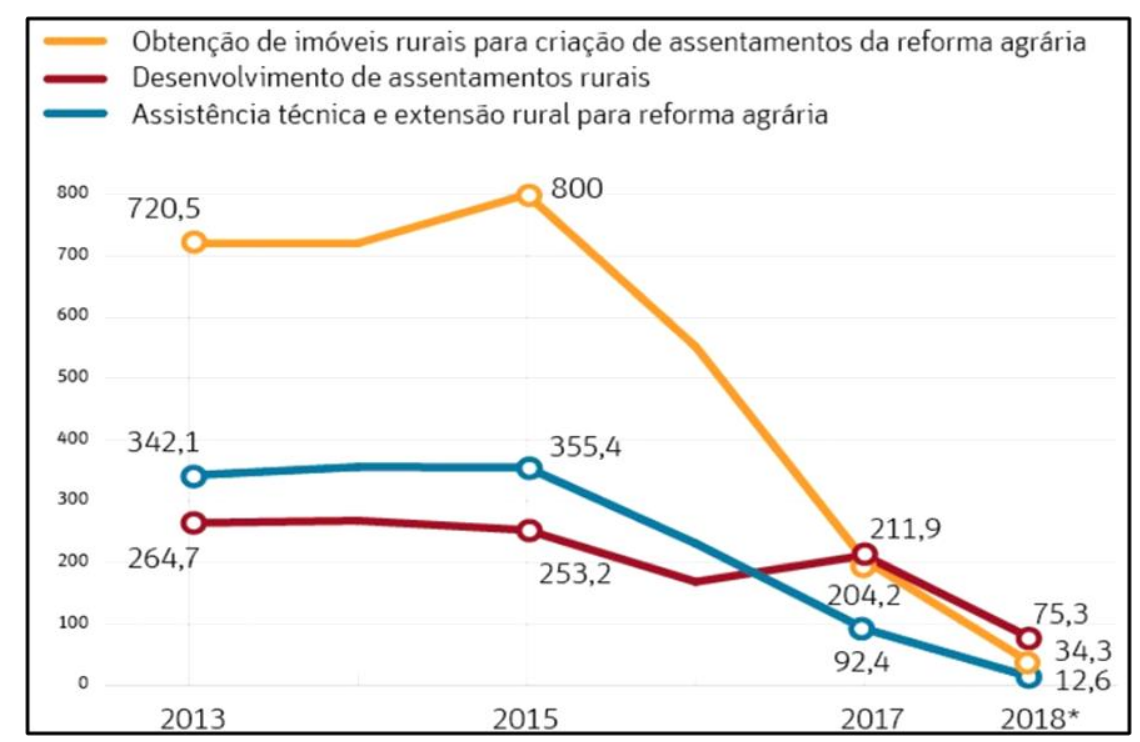

*Valores baseados no Projeto de Lei de Diretrizes Orçamentárias (PLDO) de 2018. Fonte: GUERRA e MAGALHÃES (2017)

A precarização e a extinção de políticas públicas marcam retrocessos ameaçadores às conquistas sociais alçadas nas últimas décadas e ampliam as desigualdades e o processo de concentração de terras via incorporação de novas áreas ao mercado de terras a partir da titulação sem a criação de condições mínimas de manutenção dos indivíduos na terra titulada. (PAULA, GOMEZ, TRACZ, 2017; MATTOS, 2017; CLEPS JR, 2018; NARDOQUE, MELO, KUDLAVICZ, 2018).

Este processo de sucateamento das políticas públicas voltadas para Reforma Agrária, somado à manutenção e aumento dos incentivos ao agronegócio, com maior intensidade no início dos anos 2000, agravado nos anos de 2010 e ampliado pós-2016, pode ser chamado de contrarreforma agrária (NARDOQUE, MELO, KUDLAVICZ, 2018; ALENTEJANO, 2020). É como se uma vez iniciado, este processo estivesse recebendo sequência pela gestão que assumiu o país em 2019, dando o tom ao espírito da época (Zeitgeist da proposta hegeliana), representado pelo aumento da violência no campo, pela ampliação das desigualdades, pelo fortalecimento do agronegócio e das frações de classe historicamente privilegiadas dentro deste segmento em detrimento daqueles que 
lutam por acesso e permanência na terra com condições de dignidade humana para sua reprodução enquanto sujeitos e classe social.

\section{CONSIDERAÇÕES FINAIS}

O desenvolvimento territorial e agrário brasileiro é marcado por contradições e conflitos de classe balizados pelo Estado que, por não ser neutro, atua favorecendo os interesses das frações de classe mais representativas em sua composição.

Os movimentos socioterritoriais do campo brasileiro tem papel importante no processo de consolidação das políticas públicas de acesso e permanência na terra e de Reforma Agrária no país.

As pressões dos órgãos internacionais de crédito para implantação dos princípios do neoliberalismo no Brasil colaboraram para o desenvolvimento do planejamento descentralizado, entendido por estes órgãos como importante instrumento de desoneração do Estado. Entretanto, este modelo de planejamento territorial também é entendido como forma de criar políticas a partir das bases e fortalecer o atendimento dos anseios daqueles que lutam por melhorias nas condições de acesso e permanência na terra.

O golpe Político-Jurídico-Midiático-Ruralista, orquestrado no Brasil em 2016, e o governo que assumiu o país em 2019 trouxeram consequências duras para as políticas públicas voltadas para o campo acentuando a chamada contrarreforma agrária. Apesar das dificuldades e dos problemas relacionados a este momento é preciso que haja o recrudescimento dos movimentos socioterritoriais de luta pela terra retomar suas pautas de luta e fazer frente às violências e retrocessos que o país tem sofrido recentemente.

\section{REFERÊNCIAS BIBLIOGRÁFICAS}


ALENTEJANO, P. R. R. As políticas do Governo Bolsonaro para o campo: a contrarreforma agrária em marcha acelerada. Revista da ANPEGE. v.16, n.29, 2020, p.353-392.

ALMEIDA, R. Ap. de; PAULINO, E. T. Fundamentos teóricos para o entendimento da questão agrária: breves considerações. Geografia. Londrina, v.9, n.2, p113-127, jul./dez.2000.

ARAÚJO, T. B. de. As políticas públicas no Brasil: heranças, tendências e desafios. In: SANTOS JUNIOR, O. A. dos. [et al.]. (orgs.). Políticas Públicas e Gestão Local: programa interdisciplinar de capacitação de conselheiros municipais. Rio de Janeiro: FASE, 2003. 10p.

ARRETCHE, M. Mitos da descentralização: Mais democracia e eficiência nas políticas públicas? Revista Brasileira de Ciências Sociais. v.11. n.31, São Paulo. Jun. 1996. $22 \mathrm{p}$.

CLEMENTE, E. C. O programa de microbacias no contexto do desenvolvimento rural da região de Jales-SP. 2011. 339f. Tese. Universidade Estadual Paulista, Faculdade de Ciências e Tecnologia, 2011. p. 73-135.

CLEPS JÚNIOR, J. Descaminhos da Reforma Agrária no contexto das reformas neoliberais e da crise político-institucional no Brasil. Revista OKARA: Geografia em debate. v.12. n.2, 2018. p.649-663.

COCA, E. L de F.; FERNANDES, B. M. Mecanismos de obtenção dos territórios dos assentamentos rurais nas mesorregiões Oeste paranaense e Centro-Sul paranaense 1984-2008. Núcleo de Estudos, Pesquisas e Projetos de Reforma Agrária (NERA). Ago. 2009. 12p.

DELGADO, Guilherme da Costa. Do “capital financeiro na agricultura” à economia do agronegócio: mudanças cíclicas em meio século (1965 - 2012). Porto Alegre: Editora da UFRGS, 2012. p.77-88.

FABRINI, J. E. Território, classe e movimentos sociais. Revista da ANPEGE, v.7, n.7, p. 97-112, jan./jul. 2011.

FERNANDES, B. M. Território camponês. In: CALDART, R. S. (et.al). Dicionário da educação do campo. São Paulo: Expressão Popular, 2012. p.746-750.

GUERRA, R. MAGALHÃES, A. Incra restringe recursos para assentamentos rurais. Folha de São Paulo. São Paulo. 04 out. 2017. Poder. Disponível em: 
<https://www1.folha.uol.com.br/poder/2017/10/1924119-incra-restringerecursos-para-assentamentos-rurais.shtml>. Acesso em: 22 jun. 2021.

HARVEY, D. A produção capitalista do espaço. São Paulo:Annablume, 2005.

HESPANHOL, A. N. A atuação do Estado no processo de desenvolvimento brasileiro. In: Meneguette Junior, Messias (Org.). FCT: 40 anos Perfil Científico Educacional. Presidente Prudente: FCT/UNESP, 1999, p.21-41.

JESSOP, B. O Estado, o poder o socialismo de poulantzas como um clássico moderno. Rev. Sociol. Pol. Curitiba-PR, v.17, n.33, jun 2009. p.131-144.

LUIZ, L. F.; NARDOQUE, S. Programa Nacional de Crédito Fundiário em Três Lagoas/MS: desdobramentos e entraves para a recriação do campesinato. REVISTA NERA, v.22, n.49, p.83-110, 2019.

MARTINS, J. de S. A sujeição da renda da terra ao capital e o novo sentido da luta pela Reforma Agrária. In: MARTINS, J. de S. Os camponeses e a política no Brasil. Rio de Janeiro: Vozes, 1981. p. 151-177.

MATTOS, L. M. de. Austeridade fiscal e desestruturação das políticas públicas voltadas à agricultura familiar brasileira. Análise. n.39, EMBRAPA, 2017. 43p.

MITIDIERO Jr, M. A.; BARBOSA, H. J. N.; SÁ, T. H. Quem produz comida para os brasileiros? 10 anos do CENSO agropecuário 2006. Revista Pegada, v.18, n.3, setdez 2017. P 7 - 77.

NARDOQUE, S. A relação campo-cidade: abordagem sob o prisma da questão agrária. In: SPOSITO, E. S. (et al). A diversidade da geografia brasileira: escalas e dimensões da análise e da ação. Rio de Janeiro: Consequência Editora, 2016. p. 255-286.

NARDOQUE, S. Expansão geográfica do capital e Reforma Agrária em Mato Grosso do Sul nos governos FHC e Lula. In; COELHO, F.; CAMACHO, R. S. O campo no Brasil contemporâneo: do governo $\mathrm{FHC}$ aos governos petistas (questão agrária e Reforma Agrária). Curitiba: CRV, 2017.

NARDOQUE, S.; MELO, D. S.; KUDLAVICZ, M. Questão agrária em Mato Grosso do Sul e seus desdobramentos pós-golpe de 2016. Revista OKARA: Geografia em debate. v.12. n.2, 2018. p.624-648.

OLIVEIRA, A. U. de. Geografia Agrária e as transformações recentes no campo brasileiro. In: CARLOS, A. F. A. (Org.). Novos caminhos da Geografia. São Paulo: Contexto, 1999. p.63-110. 
ORTEGA, A. C; CERQUEIRA, C. A.; SILVA, F. P. M. da. Planejamento, desenvolvimento e descentralização: o papel do estado no desenvolvimento territorial. In: ORTEGA, A. C.; PIRES, M. J. de S. (ORG.) As políticas territoriais rurais e a articulação governo federal e estadual: um estudo de caso da Bahia. Brasília: IPEA, 2016. p. 17-28.

PAULA, A. M. de; MONTENEGRO GOMEZ, J. R.; TRACS, C. A. M. Novo ciclo neoliberal no Brasil: desmontando as políticas públicas para a agricultura camponesa. Revista Pegada, Presidente Prudente, v.18, 2017. p.57-88.

PAULINO, Eliane Tomiasi. Territórios em disputa e agricultura. In.: FABRINI, J. E., PAULINO, E. T. (org.). Campesinato e territórios em disputa. São Paulo: Expressão popular, 2008. p.213-238.

Submetido em: 10 de setembro de 2021

Aprovado em: 03 de dezembro de 2021.

Publicado em: 23 de dezembro de 2021. 